\title{
Study on the Application of Accounting Prudence Principle in Tea Industry under the Background of Regional Economic Development in Northeast China
}

\author{
ShiRong QIN \\ School of accountancy, \\ Harbin University of Commerce \\ Harbin, China \\ e-mail: sdqsr@163.com
}

\begin{abstract}
In the process of vigorously advocating the development of the Northeast regional economy, along with the enhancement of the economic foundation of the northeast region and the eclectic diet culture, tea enterprises have become the new favorite in the economic tide. Encourage the growth of tea enterprises not only for the Northeast regional economic development to inject new vitality, but also conducive to the promotion of Chinese culture to the world. In recent years, our country actively for tea export provides a good environment for development, but with the rapid growth of the market economy risk changes more and more complex, which requires the tea enterprises to estimate and forecast the full range of possible development in all kinds of risk and loss of assets, which is to study the application of the principle of prudence in accounting for tea enterprises in the management of early heart. The cautious principle point of view, the current status of the application of the principle in the tea enterprises in accounting work and effectiveness were dissected and analyzed and put forward some methods and suggestions about the application of the principle of prudence on the principle of prudence from a dialectical point of view.
\end{abstract}

Keyword-regional economies; accounting; prudence principle

\section{THE CONNOTATION AND FUNCTION OF ACCOUNTING CONSERVATISM}

The so-called principle of prudent accounting refers to accounting confirmation, measurement and report on related matters of the transaction should be cautious attitude is a kind of objective, can not overstate assets or income, nor understate liabilities or expenses. So, does it mean that the application of prudent principle is a prevention and control of risk of universal paste it, the answer is obviously negative. Everything has its two sides, the principle of prudence is no exception, which requires us to dialectically understand the role of caution: From the positive side, the principle of prudence to help enterprises must face the maximum to avoid competition in the market risk or crisis, protect the future survival and development of space enterprise, make the enterprise retained enough reserve force, lay a solid foundation for the sustainable development of enterprises, improve the market competitiveness of enterprises, is conducive to the protection of creditors and the interests of investors, to reduce the risk of the contract interest; On the negative side, the principle of prudence may have different levels of conflict with other accounting principles, contradicts the principle of prudence and other accounting principles, enterprises should make correct judgment on the importance of the principle, in order to ensure their order of priority. For example, because of the contradiction between the objectivity principle and the principle of prudence, the principle of prudence should be carried out under the principle of objectivity; When the principle of prudence and the accrual principle of conflict, should be based on the principle of prudence is preferred, because the sound operation of an enterprise, related to the enterprise to survival and development, than on an accrual basis to determine the revenue and costs are attributable to the period is much more important. And other principles of priority, according to the actual situation to determine.

\section{After MAKING Clear the Role of PRUdence PRINCIPLE IN TEA ENTERPRISES, We SHOULd PAY Attention to the Problems to Be Solved}

\section{A. High Agency Costs}

For tea enterprises, the product itself is very strong regional, for example, the best place Longjing green tea of West Lake; people first mentioned Dahongpao comes to mind Wuyishan; another example of Lu'an Guapian, Anxi Tieguanyin Tea, this is not the only one. This determines the tea enterprises can not set up their own factories in all places, and the market demand and must be multi-level. Different consumer preferences are different, even if the same consumer for different seasons of consumer preferences are also different. So it is necessary to promote tea enterprises in the existing mature sales channels on the basis of, if the intention to enrich the variety of products, the expansion of sales performance to inevitably face the agent of other regional manufacturers of products. And the cost of each agent is expensive tea. This is the objective of the cost of amortization and put forward higher requirements. This is the objective of the cost of amortization and put forward higher requirements.

\section{B. Low Utilization of Assets}

Update the equipment in most cases will improve the efficiency of production. However, in the production process, due to asset management accounts are unknown, some tea enterprises often repeat the purchase of certain machinery 
and equipment. The repeated purchase of assets will undoubtedly greatly increase the production costs of tea enterprises, seriously affecting the development of enterprises. There are some tea enterprises because there is no regular maintenance and maintenance of the equipment, making their useful life greatly shortened. The occurrence of these cases pulled down the utilization rate of tea enterprises assets, and the low utilization rate of enterprise assets will undoubtedly make the quantity and quality of tea production affected. Therefore, the reasonable depreciation of assets has become a problem to be solved.

\section{Tea Enterprises to Improve the Accuracy of Cost Measurement}

It is very fragile to combine the accounting prudence with the management of the account. Therefore, both in the production process and in the transportation, the enterprise must be careful. Nevertheless, in this series of processes, the loss of tea is inevitable. In view of this situation, in the asset management of tea, it is necessary to provide the necessary provision for impairment. In order to ensure that the production of tea is not underestimated, so that the actual tally. For transportation costs on the way, companies should also be included in the corresponding accounting subjects, and can not be included in the cost of them, so as not to overestimate the cost of tea prices. For tea production equipment, it should be included in the fixed assets of the enterprise. A detailed record of assets not only makes the accounts of the enterprise more clear, but also greatly reduce the workload of the management of the latter. As a result, the cost of tea enterprises will become more convincing management.

\section{The Objectivity and Timeliness of Accounting Information Hinder the Tea Enterprises to Join the Internet Financial Platform}

At present, China's tea enterprises in the actual operation process of asset management is the main form of accounting vouchers, accounting vouchers, account summary summary, journal ledger sheet, which are large and medium-sized enterprises to adopt two kinds of tea after the asset management form, characteristics of these two forms is a distinct sequence the order is very smooth and cohesion between the different positions in the accounting work, to one-to-one correspondence between documents, books and financial statements, with a high degree of consistency. Although this kind of management style has a strong error correction for the flow of funds, "name", but the lack of pertinence and validity, the traditional form is too oldfashioned, has been unable to adapt to the Internet era, the digital age of science and technology, the requirements of the times, it is easy to cause the defect of accounting information, is not conducive to expanding the scope of tea enterprises and market share increase, is not conducive to the healthy development of tea enterprises. The early Internet financial financial services for the tea industry is limited to the third party payment practice shallow, in recent years, the Internet Finance in addition to "direct financing" with respect to the tea injected fresh blood also with the help of outside finance, big data analysis technology, networking technology, realizing the integration of production, processing, from the financing platform packaging, marketing, logistics, marketing and other functions, is a kind of integrated marketing. In this integrated marketing mode, the traditional tea industry chain has been effectively integrated in the vertical direction, reduce the various marketing communication departments, lack of coordination because of repeated materialism has caused, also increased the marketing financing system and realize the efficient operation of integrated marketing, effectively reducing the transaction cost of marketing. However, want to participate in the first to ensure that the relevant parties to provide objective and timely data, and the data, information generation must follow the principle of prudence.

\section{E. Lack of Awareness of the Lack of Risk Awareness of the Lack of Specialized Asset Management}

One of the problems in the process of asset management is that there is no special management department. Because asset management contains a wide range of content, the details need to be considered very much. So now, some tea enterprises do not want to set up such a sector. Therefore, some of the assets of tea enterprises are jointly managed by a number of departments, while others are not interested. In this case, tea prices for their own assets can not be strictly divided. Therefore, even if there is a problem in the tea business assets, can not find out the specific reasons. Many employees in order to evade and shirk responsibility, the problem of turning a blind eye to the problem, the problem will eventually evolve into a big problem, resulting in very serious consequences.

\section{THE APPLICATION OF TEA ENTERPRISES TO THE PRINCIPLE OF PRUDENCE}

\section{A. Reasonable Determination of the Inter Period Amortization and Amortization of Expenses Based on the Principle of Prudence}

For the large one-time cost of the first, to determine a reasonable period of amortization or withholding, namely the benefit period clearly the expenditure is a month or several months, it may be a year or several years, there will be some accounting period to share the burden of costs included in an accounting period, and vice versa; secondly, to fully consider the effectiveness of the benefit of time, time is the time of the cost benefit can achieve the expected longer; finally, to adopt reasonable measurement method to determine each should bear the costs of.

\section{B. Follow the Principle of Appropriate Application}

Although the principle of prudence in essence has two sides contradictory, but not choking. It is true that the excessive use of the principle of prudence will lead to a high degree of debt and cost estimates in the future accounting period. But it is an indisputable fact that the principle of prudence can avoid the potential market risks and protect the fundamental interests of enterprises. As long as the principle of moderate application, the principle of prudence in 
accounting for the operation of tea enterprises escort. For example, the depreciation of fixed assets of tea enterprises, in accordance with the principle of prudence in the flat speed and accelerated depreciation method to choose accelerated depreciation, that is, double depreciation can be.

\section{The Combination of Accounting Conservatism and Budget Management}

In the case of tea enterprises can not fully grasp the market dynamics, if you do not do a good job in the budget management of assets, tea prices are usually in a very passive state. For example, the production of tea will be affected by the weather, in the peak period of heavy rain and snow, tea enterprises need to come up with the funds to purchase the necessary protective equipment. For this expenditure, tea enterprises should make a reasonable budget in advance. At the same time, in real life, tea prices usually refer to the past budget. But in the face of the current vagaries of the market environment, this budget model is clearly not accurate enough. Therefore, according to the principle of prudence of the enterprise, according to the change of market environment and make timely adjustments to the tea enterprises to obtain new opportunities, but also can greatly improve the utilization rate of assets.

\section{Improve the Quality of Accounting Personnel to Grasp the Application Scale}

Strengthen the accounting professional ethics education, to promote the accounting staff to practice a solid basic skills, professional knowledge and practical experience to deal with the economic business, become a business management staff. Accountants should be strict with themselves, not only to constantly update the professional knowledge, strengthen follow-up education, but also focus on the accumulation of experience in order to adapt to the changing economic environment. In addition, the enterprise management should also have the awareness of the guidance of accounting personnel to make full use of the principle of caution given the autonomy of enterprises, determine the reasonable choice of accounting policies, accounting methods properly, ensure the reasonable application of the principle of caution.

\section{E. Establishing Long Term Evaluation Mechanism to Strengthen Supervision and Management of Human Assets}

Tea enterprise human resource is owned in the business process to improve business performance and create value from the general term of all talents contribution for enterprise development, including education, production, maintenance, trading, management personnel. It will make great contribution for the enterprise to realize the maximization of the value of the expected profit and the enterprise assets. The rational use of talents depends on the correct management of human assets. Therefore, to strengthen the supervision and management of human assets, to ensure the expected profit. The existence of accounting personnel is the necessary condition to ensure the effective management of tea enterprise assets. However, the employment of accounting personnel can not be completely accepted and applied without principle. Hire the accounting personnel of tea enterprises should be "have the ability to live", the only way to ensure prudent accounting objective, complete the internal tea enterprise asset management accurate accounting of safety cost, time value of money, to ensure the efficient operation of the enterprise based on my more assets, improve the performance of security tea enterprises. To do this, it is necessary to establish a long-term assessment mechanism for the internal use of the accounting staff of the tea industry, the use of reasonable.

In fact, in the whole process of accounting in tea enterprises will follow the principle of prudence, not only limited in asset management, which is decided by the nature of the accounting profession. For example, mode and standard accounting of tea enterprises shall be reasonable and scientific, safe, measurement of assets shall not be overvalued or profits, and in the development of all kinds of accounting report should be objective, comprehensive and detailed for each part of the assets, liabilities, costs and income to be disclosed. The application of the principle of prudence in the asset management of tea enterprises is to meet the needs of the enterprise's sustainable development. The application of the principle of prudence as "Minyan fine umbrella, filled with food" metaphor, to the maximum extent, help enterprises to avoid risks and potential crisis in the fierce market competition. Through the principle of prudence, the tea enterprises can control the assets, and can keep the competitive advantage of the enterprise as far as possible, and maintain enough space for survival and development. Prudent management of assets can also be counterproductive in the firm's strategic decision-making and prudent, which is responsible for corporate creditors and investors. On the other hand, the uncertainty of accounting management is one of the reasons for the application of the principle of prudence. The activities of the enterprise will sometimes appear in the period of the capital, cost or income and other projects, which requires the use of accounting estimates in the current accounting methods, the existence of the estimation of the accounting treatment of instability. And whether the estimate is scientific and reasonable will affect the accuracy of the asset, cost and profit in the future. In order to make the estimation can be confined to a real and objective scope, the application of the principle of prudence becomes inevitable.

To sum up, in the severe market environment, it is of great significance to combine the accounting conservatism with the asset management of tea enterprises. Only in this way, the tea enterprises in time to know their current assets, the reasonable conduct of the work of asset management. Only in this way, tea enterprises can make correct and reasonable investment decisions. I hope that through this study the asset management of China's modern tea enterprises plays an instructive role, also hope can let the enterprises to flourish through effective asset management, China's tea culture to further afield.

\section{REFERENCES}

[1] Zhang Xu. Research on corporate finance culture in China [D]. Shanxi University of Finance and Economics 2014. 
[2] Chen Ke. 'Pu'er Tea + Finance + Internet' innovation of tea circulation pattern [J]. tea, 2015 (12): 76-77.

[3] Of China's tea enterprises development suggestions for [J]. market modernization, 2014 (33): 18-19.
[4] On the current situation and Countermeasures of enterprise asset management [J]. modern economic information, 2015 (4Z): 227

[5] Lu Ailin enterprise asset management problems and measures [J]. modern economic information, 2014 (16): 276.78. 